\title{
LA CONFRONTACIÓN: UNA OPORTUNIDAD PARA EL DESARROLLO PERSONAL
}

\author{
Zoila Rosa Vargas Cordero
}

Recibido 7-XI-2003

Resumen: Este artículo pretende apoyar al profesional en Orientación u otros profesionales de ayuda que se inician en el campo laboral y que necesitan desarrollar mayores destrezas personales para utilizar la confrontación vista como una técnica estratégica, que fundamentada desde diferentes enfoques psicológicos para la Orientación, se convierte en una herramienta de gran utilidad en la ayuda de las personas que muestran diferentes conductas, tales como, dificultad para interactuar con sus semejantes, limitado compromiso personal y empobrecida conexión con la realidad, entre otras; en donde la confrontación resulta un medio eficaz y una oportunidad para el desarrollo personal a partir de la integración del yo.

Palabras clave: Confrontación, Responsabilidad Profesional, Aprendizaje, Desarrollo Personal.

\section{Introducción}

En cualquier interacción humana, las oportunidades para la confrontación son ilimitadas y el desarrollo personal, o crecimiento emocional requiere de una serie de infinitas auto confrontaciones que conllevan dolor e incertidumbre, esto a su vez conduce a mostrar cambios conductuales.

La definición social más popular y difundida de confrontación es entendida como un choque relativamente violento entre fuerzas opuestas, y tiene como propósito reducir la ambigüedad e incongruencias en la experiencia y comunicación de la persona.

El énfasis emocional de esta definición social interfiere tanto con el pensamiento como con la acción, tal vez correr los riesgos de la confrontación parece más difícil de lo que es. Se aprende mejor haciendo, si se rechaza el comprometerse con una conducta, se limitan las oportunidades de aprender.

La intención de este artículo es señalar algunas áreas posibles de confrontación para el profesional en Orientación, que puedan ser útiles en los procesos de Orientación y que implicarán en alguna medida menores grados de riesgo para la persona orientadora que está menos segura de sus destrezas en este campo. 


\section{El mensaje en la comunicación}

En la comunicación diaria, muchas personas son inconscientes de las incontables veces que el contenido acusativo de un mensaje parece tener prioridad sobre la comprensión y acción de ambas partes. Los sentimientos de la otra persona frecuentemente son ignorados en una lucha por defenderse, o por señalar la culpa. Si cada persona se toma el tiempo para analizar lo que se dijo, podrían ser conscientes del contenido total del mensaje, pero en la comunicación cotidiana tal análisis es poco frecuente. Lo más usual es que el mensaje, interfiera con la comunicación antes que facilitarla.

Culpar a la otra persona disfraza los sentimientos que se expresan. Esta conducta es descrita por diferentes autores como (Satir 1990), (Rizo 1998), (O’Connor 1996) de la siguiente manera; los hábitos utilizados en las conversaciones reflejan cómo las personas fracasan en éstas por no asumir responsabilidad por sus propios sentimientos y conductas.

A menudo, en conversaciones diarias se pueden oír frases parecidas a estas "El me hace sentir mal", "Ella me hizo hacerlo" y "Ella o él no me gusta". Todos estos mensajes lanzan a otros la culpa por los sentimientos personales. Mensajes como los anteriores se definen como mensajes en segunda o tercera persona; esto es, expresan sentimientos como si fueran causados por otros.

Como regla, muchos mensajes en segunda o tercera persona obstaculizan la comunicación porque proporcionan dos tipos diferentes de información en el mismo paquete. En contraste, un mensaje en primera persona se define como una expresión directa de los sentimientos propios, lo cual permite responsabilizarse por ellos.

Cuando las personas niegan sus sentimientos y responsabilidades proyectan los conflictos internos en otros, culpan a los demás de su mala suerte y se les dificulta llegar a reconocer alguna fuente de felicidad. Practican lo que para Satir (1990) significa "contacto" que se refiere al diálogo exterior, o patrón de conducta generalizado que se emplea en las relaciones interpersonales cuando las personas conocen únicamente la máscara que se lleva puesta.

Si el individuo habitualmente utiliza mensajes en segunda o tercera persona, está tácitamente reconociendo una pérdida de control sobre un elemento muy importante de la existencia: los sentimientos, y si las personas se rehúsan a tener control sobre éstos y sus vidas, se sitúan y caracterizan a sí mismas como víctimas.

A tal punto que profesionales de ayuda que no estén alertas, pueden experimentar lo que en el análisis transaccional se denomina "juegos en los que participamos", (Jongeward, 1990) los cuales son sutiles y poderosos e implican el principal intento manipulativo de las personas para atraer, dentro de su percepción de la realidad de una determinada situación, a esos profesionales.

Karpman en su momento sugirió otro tipo de juego que es no menos dañino a la comunicación, el triángulo dramático; significa que el profesional puede llegar a ser un aliado, destruyendo la efectividad de su ayuda, al convertir repentinamente la posición inicial propia del orientado "yo contra el mundo", en la nueva posición "nosotros contra el mundo". Según esto, los profesionales llegan a verse comprometidos, desde lo personal por una atracción hacia el problema, en situaciones profesionales que reclaman la confrontación.

Esta atracción resulta dañina para ambas partes, para la persona orientada porque la conducta ineficaz es reforzada aumentando la probabilidad de que se continúe con la misma conducta y para el profesional u orientador, la manipulación por parte de la persona orientada para convertirlo en aliado, lo ubica en total desventaja puesto que el método utilizado para hacerle frente a esa realidad en la relación no es funcional. 


\section{La confrontación}

Es vista como una técnica o herramienta utilizada desde diferentes enfoques de la Orientación, razón por la que resulta importante que estos profesionales valoren la necesidad de adquirir las destrezas personales para la confrontación y la manera en que puedan utilizarla y enseñarla a quienes orienta.

En todo modelo terapéutico de Orientación tienen un papel esencial las técnicas de interrogación, así Bandler y Grinder en Rupprecht (1998) mencionan como parte de su metamodelo del lenguaje la técnica de interrogación, cuyo objetivo es que el cliente descubra las generalizaciones, eliminaciones y/o distorsiones dentro del nivel del entorno, la conducta y las capacidades.

Ellis (1983) la denomina técnica socrática, es un método muy activo que trata de desafiar las opiniones de la persona; la conduce a que reconozca, examine y abandone esas ideas $u$ opiniones irracionales. Por su parte Rogers (1989) propone el "reflejo de sentimiento", éste trata de sacar a la luz la intención, la actitud o el sentimiento inherentes a las palabras del individuo.

Para González y otros (1978) es considerada una táctica que consiste en llamar la atención de la persona acerca de una situación particular, llevarla a reconocer detalles significativos que ha estado evitando para que pueda clarificarse.

Puede decirse entonces, que la confrontación es una forma psicológica de interrogar, que apunta a obtener detalles cognitivos y sensoriales precisos de la persona para ayudarla a centrarse en su propia vivencia interna y así ésta logra sacar a la luz aquellos pensamientos, sentimientos y actitudes cargados emocionalmente que le producen conflictos.

La utilización tiene el fin de conducir a la persona hacia una reorganización del patrón referencial básico, a percibirse a sí misma y a su entorno de diferente manera, aceptando la responsabilidad por la propia vida y la consideración por otros, lo cual la conducirá a mostrar una conducta más racional basada en el interés de transformarse y crecer emocionalmente.

Esta técnica ayuda a la gente a ver más claramente lo que ocurre en ella, las consecuencias de su conducta y cómo puede asumir responsabilidad para cambiar hacia una vida más eficaz, a desarrollar más y mejores relaciones con otros, puesto que cada quién debe aprender a vivir en contacto consigo mismo y a su vez cada persona en contacto con la otra, (Saint Paul y Tenenbaum 1996); (Satir 1990).

Es un reto proponerse examinar, modificar o controlar algunos aspectos de la conducta y aunque la persona confrontada generalmente presenta una reacción de defensa, por las implicaciones emocionales que conlleva, casi siempre resulta difícil y penoso aceptar la confrontación, sin embargo es terapeúticamente beneficiosa, promueve la acción correctiva y a su vez el desarrollo personal.

Muchos profesionales muestran cautela en el uso de la confrontación por considerarla riesgosa, ya que precipita la crisis, y esto puede conducir a las personas a mostrar un comportamiento hostil, resistente y defensivo, sin embargo una buena confrontación no despoja al confrontado de sus defensas y dignidad, (Ellis, 1983).

Por el contrario, la experiencia adquirida en la práctica, indica que si bien es cierto la confrontación produce crisis, también es cierto que mueve los recursos personales internos, para crear nuevas y mejores respuestas. La confrontación bien utilizada es eficaz y con mucha probabilidad tiene como resultado mayor respeto, mejor comunicación, comprensión mutua en la relación orientadora y más amistades significativas en la vida de todo ser humano que se exponga a ella. 


\section{Responsabilidad del profesional en orientación}

Sin duda la buena confrontación requiere destreza y demanda mucha capacidad del profesional para saber cuándo y cómo se debe confrontar.

Este debe, antes de confrontar a otra persona, al igual que en todos los procesos de ayuda, confrontarse consigo mismo, ser honesto y responsable en sus respuestas, además de reconocer sus áreas vulnerables.

A continuación se presenta una guía para la auto confrontación del profesional; hacerse preguntas tales como las que se mencionan, pueden ofrecer más seguridad personal y responsabilidad en el uso de la técnica:

¿Realmente tengo el derecho y la obligación para confrontar?

¿Estoy completamente seguro de mi razón para confrontar?

¿Qué riesgos hay para el orientado?

¿Tendrá esta confrontación consecuencias positivas para el orientado?

¿Qué riesgos hay para mi como persona y profesional?

frontar?

¿Es este el mejor momento para con-

¿Podré conducir adecuadamente esta confrontación?

¿Podré mantener la ecuanimidad y no reaccionar defensivamente?

Además, es importante para este profesional creer y plantearse algunos supuestos acerca del ser humano en y para la relación de ayuda: un supuesto básico sería creer que la persona es potencialmente capaz, y además su estado emocional le permite esta experiencia.

Que la confrontación, le permitirá a la persona confrontada, llegar al menos a una respuesta con el máximo de responsabilidad personal.

Que la persona está dispuesta a asumir la responsabilidad y las consecuencias de los propios actos con preocupación sincera y apertura para el cambio.

Que puede llegar a reconocer y debatir su conducta irracional para transformarla en racional.

Lo anterior hace posible confrontar de manera útil y no usar excusas para no hacerlo. La ausencia de confrontación en una relación de ayuda puede comunicar falta de compromiso con la persona que orienta.

Otra de las responsabilidades del profesional en Orientación para confrontar es la honestidad para identificar las propias habilidades, saber que está en capacidad de prestarle atención a las expresiones verbales y no verbales porque esto es fundamental; cuestionar desde el inicio hasta el final; acercarse y retirarse durante el proceso de auto descubrimiento; y devolverle al orientado únicamente los propios mensajes manifestados.

Solamente cuando se sienta seguro de sí mismo y de poder hacerlo, lo podrá hacer eficazmente y ayudar al orientado a ser más responsable para enfrentarse a su yo de una forma real, que aunque dolorosa, no lastima su autoestima, entonces estará listo para hacerlo. Se necesita un "darse cuenta" de los comportamientos, gestos y reacciones emocionales que se pueden producir, es decir estar en contacto íntimo consigo mismo para poder comprender y entrar en contacto con los otros.

\section{El aprendizaje de la técnica, confrontación}

Como la confrontación es directa, la expresión de las emociones de la persona serán genuinas y también directas, que la convierte en una relación de cuidado y algunas veces difícil, por lo que es importante aprender a emplearla; saber cuándo y cómo se debe confrontar.

La confrontación como táctica, es entendida como una habilidad que puede 
emplear el profesional en Orientación para enfocar discrepancias, aclarar informaciones o percepciones erróneas, o identificar patrones conductuales inadecuados y entonces motivar al orientado a poner en orden algunas cosas y actuar más constructivamente.

Desarrollar las destrezas para la confrontación en algunos casos en innata, las personas poseen gran habilidad para este tipo de comunicación y para quienes no la poseen, si deberán tomar conciencia que es una habilidad que requiere de mucha consistencia en la práctica. No se aprende sólo con la lectura. Práctica, observación, supervisión y evaluación se hacen necesarias.

Una buena confrontación se origina en el deseo de quien confronta de atender más profundamente a la persona que confronta, por lo tanto debe basarse en una verdadera comprensión de esa persona orientada y surgir de un interés que sea genuino y claro, ya que comunica el más alto nivel de comprensión empática. Debe ser vista como un acto de afecto y compromiso.

El fin principal que persigue el uso de esta técnica es concreto, es dejar a la persona con el mínimo de ansiedad, angustia y culpabilidad; con suficiente capacidad para dejar de culpar a los demás y al entorno de sus conductas y acciones.

Lo anterior hace que algunas veces sea más difícil emplearla y no es eficaz en todas las personas, principalmente con aquellas que se ubican en los extremos ya sean pasivas o agresivas.

No obstante, son muchos elementos que se deben tomar en cuenta, ya que son muchas las formas utilizadas para confrontar: depende entre otras cosas, de las personas, de la situación y del enfoque psicológico para la Orientación en que se basa la relación; seguidamente se mencionan algunas:

- Sólo aquellos profesionales que han resuelto los propios sentimientos negativos que interfieren en su vida y se sienten comprometidos con su propio desarrollo personal se atreven a confrontar creativa y constructivamente para beneficio mutuo.

- El profesional necesita tomar en cuenta el impacto que la confrontación puede tener en la persona orientada y estar en disposición de asumir las consecuencias de esa intensa interacción emocional que se produce.

- Es necesaria una disposición de riesgo y entusiasmo para identificar y analizar ideas irracionales. De ahí qué es importante invitar al orientado a que observe el propósito de su conducta, esto lo conduce a una auto confrontación.

- $\quad$ Es importante ser consistente en el uso de la técnica, durante el proceso de Orientación, ya que una sola confrontación posiblemente no altera el patrón habitual de conducta de la persona confrontada y en contraste, una respuesta empática buena y con cierto nivel de profundidad y constancia, a menudo resulta ser una buena confrontación.

- Durante los primeros contactos, progresivamente se produce un rapport, empatía necesaria para proceder entonces a confrontar, es decir que una confrontación prematura usualmente puede generar sentimientos y actitudes negativas tales como defensa, enojo, manipulación y muy probablemente se puede hasta destruir la intención y la relación de ayuda.

- Ser asertivamente afirmativo también se convierte de manera especial en confrontación, porque la afirmación puede ser vista como un acto de preocupación cuidadosa y genuina por parte del profesional, con lo cual 
se puede ayudar a la persona a abandonar actitudes defensivas.

- Ser simpático no funciona en el empleo de la confrontación, más bien resulta destructivo para el desarrollo personal de la persona orientada. Se necesita más bien la compasión, vista ésta como una preocupación por el sufrimiento de otros con el deseo de ayudarles y aliviarles. (Bisquerra, 2000).

- Un interrogatorio lento y minucioso resulta más suave, de menos riesgo, pero a la vez más costoso, y una entrevista en la que la persona se sienta confundida o agredida por el tipo de pregunta que se le plantea, no funciona; por lo tanto se hace necesario un entrenamiento en comunicación asertiva para garantizar que la confrontación se mostrará ante el orientado con firmeza y no con agresividad. (Rogers:1984; Ellis:1983).

Todo profesional en Orientación puede aprender acerca de la técnica, así como desarrollar las destrezas necesarias para emplearla tanto en sus relaciones interpersonales como profesionales. Para ello, como ya se ha mencionado, se requiere estar en contacto íntimo con los verdaderos sentimientos y necesidades de sí mismos y una disposición autocrítica para identificar y asumir con responsabilidad sus propias características personales y, sincera y genuinamente aceptar si posee las destrezas para tal efecto.

\section{Utilidad de la confrontación}

El desequilibrio emocional y dificultades para las relaciones interpersonales se producen, muchas veces, cuando no se reconocen como suyos los sentimientos y emociones que se experimentan. Tampoco se asume responsabilidad alguna por las acciones y conductas mostradas ya que las personas generalmente no se percatan de los juegos que juegan, ni de las confusiones que con ellos producen. (Jongeward, 1990).

$\mathrm{Al}$ ser confrontadas, las personas aumentan la capacidad de percatarse de la realidad, las reta a actuar de manera constructiva, por lo tanto pueden integrar las partes incongruentes y disonantes de sus vidas, identificar sus mensajes contradictorios, evaluar lo inadecuado así como las consecuencias, hasta poder desarrollar acciones más consistentes y congruentes con su sentido de vida.

También con la confrontación se ayuda a romper con las limitaciones impuestas por ellas mismas para su propio desarrollo personal. Las personas al reconocer esas conductas manipuladoras, los patrones familiares y sociales asumidos para sobrevivir en otras etapas de la vida y poco adecuados e ineficaces para el momento, los cuales han afectado la comunicación y las sanas relaciones interpersonales, se visualizan como personas fortalecidas para aceptar ese paso a otro nivel de su desarrollo personal.

La participación en un proceso de ayuda en que se utilice esta técnica se convierte en adecuadas vías para que las personas obtengan un nuevo aprendizaje de sus vidas y puedan dirigirlas de manera eficaz y responsable. Aprenden a determinar qué sentimientos tienen que expresar, la forma adecuada de compartirlos y con quién han de hacerlo. Asumir sus conductas, pensamientos y sentimientos les ayuda a aceptar la responsabilidad, dominar el problema o situación conflictiva, lo cual significa poder dar el paso esencial para alcanzar la integridad personal, esto es integrar su yo interno incluidos sus sentimientos, con el yo externo incluida su realidad contextual y de esta manera darle un nuevo sentido a su vida.

Según (Engler, 1996), la integración necesariamente implica reconocer como 
propios los sentimientos y responsabilizarse por los actos. Otros autores como O'Connor (1998) la denominan, crecimiento emocional con el cual las personas logran desarrollar técnicas efectivas para solucionar sus problemas y empezar a sentirse liberadas del dolor emocional.

\section{Conclusiones}

Para terminar se concluye que una confrontación es una técnica de cuidado por lo que siempre se aplica como parte de un proceso, con base en un enfoque psicológico para la Orientación y no dudamos que bien empleada resultará muy provechosa tanto, para la persona orientada como, para el profesional en orientación.

Una confrontación siempre debe ser honesta, por lo que el profesional que la utilice debe aprovechar la oportunidad para comunicar interés, cuidado, preocupación, halagos, y hasta afectos, y así las personas podrán sentirla más suave y por lo tanto favorable para que afloren y se reflejen las reacciones emocionales. Recuérdese que es un instrumento efectivo para aumentar la capacidad de la persona orientada a percatarse de sus limitaciones.

Con la confrontación no se trata de revelar las debilidades personales, más bien se trata de situarse por voluntad propia, en lo que podríamos denominar el banquillo de los acusados, para empezar a buscar las debilidades, encontrar obstáculos, e identificar todos aquellos sentimientos y acciones que le producen a la persona malestar y frustración, con el único propósito de que llegue su mejoramiento personal.

Todo lo anteriormente señalado propone a estos profesionales que no se pueden olvidar de lo difícil que resulta encararse honestamente a uno mismo, ya que nadie disfruta de sentirse debilitado e inseguro, de lo difícil que resulta la aplicación adecuada de esta técnica, así como lo dolorosa que puede volverse la vulnerabilidad.
No obstante, se concluye que el uso de esta técnica en los procesos de ayuda puede resultar doloroso y hasta vergonzoso para las personas que se exponen a ella, con el fin de superar las situaciones problemáticas que enfrentan, pero a la vez se percatan que el profesional en Orientación se preocupa e interesa por ellas y pueden auténticamente percibir a éste como lo que es: una persona comprometida con su quehacer y que realmente ayuda.

\section{Referencias bibliográficas}

Bisquerra, R. Educación Emocional y bienestar. Praxis: Barcelona. 2000.

Engler, B. Teorías de la personalidad. Mc. Graw Gill: México. 1996.

Ellis, A. Manual de terapia racional emotiva. Editorial Desclee: Bilbao. 1983.

González, J., Velasco, M.; Silberstein, K. Dinámica de grupos: Técnicas y tácticas. Editorial Concepto: México. 1978.

Jongeward, D., y Seyer, P. En busca del éxito. Limusa: México. 1990.

O'Connor, N. Como crecer cuando ya has crecido. Sirio: Buenos Aires. 1994.

Pichón, E. El proceso grupal del Psicoanálisis a la Psicología Social. Nueva Visión: Argentina. 1985.

Riso, W. De regreso a casa. Editorial Norma: Colombia. 1998.

Rogers C. El camino del ser. Troquel: Argentina. 1989.

. Orientación Psicológica y Psicoterapia. Narcea: Madrid. 1984. 
Rupprecht, W. La PNL y la imaginación. Sirio: Barcelona. 1998.

Saint Paul, J. Y Tenenbaum, S. Excelencia mental, La programación neuro- linguística. Ediciones Robinbook: Barcelona. 1996.

Satir, V. En contacto íntimo. Editorial Concepto: México. 1990.

Zoila Rosa Vargas Cordero Directora de la Escuela de Orientación y Educación Especial 